

\title{
Indian Contribution to Language Sciences in Non- Western Tradition: With Reference to Arabic
}

\author{
Rahmadsyah Rangkuti ${ }^{*}$, S. Imtiaz Hasnain ${ }^{2}$ \\ ${ }^{1}$ Department of English University of Sumatra Utara, \\ ${ }^{2}$ Department of Linguistics Aligarh Muslim University
}

\begin{abstract}
Language study relates itself to both ontology and epistemology. Both ontological and epistemological investigations have been the subject of debate and discussion in different civilizations producing a number of grammatical traditions other than the West. Arab, China, India and the ancient Near East can also boast of language traditions of greater antiquity. In terms of richness of insight and comprehensiveness of scope, both India and the Arab compete on equal terms with the West, where each grew independently of the others and for the most part developed separately, drawing on the resources of the culture within which it grew. Hence, there is strong need to have a study of comparative grammatical theory to which Indian, Arabs and Chinese also belong, centering on the questions of: What has been the importance of these theories explanatory categories appear in historically unrelated linguistic theory, and if they do, why? This perspective would bring new dimension to the study of linguistic theory and would not remain at the level of redressing the overwhelming emphasis on the European tradition in the study of history of linguistics.
\end{abstract}

Keywords: Arabic, Epistemology, Indian Contribution, Non-Western Tradition, Ontology

Received [15 May 2018] | Revised [22 July 2018] | Accepted [13 August 2018]

\section{Introduction}

Any discourse on the contribution of India to Language sciences inevitably brings a binarity of non-West vs. West and anticipates looking into non-Western grammatical tradition to the study of language sciences. The non-Western grammatical tradition assumes a hyponymous status where one has the liberty to assume all those grammatical traditions that are part of non-west, such as Buddhist grammatical tradition, Chinese grammatical tradition, Arabic grammatical tradition, etc. In this paper both the Indian and the Arabic grammatical traditions are subsumed. Both these traditions are like a proverbial story of Chinese emperor who once ordered a tunnel to be bored through a great mountain. The engineers decided that the best and quickest way to

\footnotetext{
*Corresponding author at: Department of English Faculty of Cultural Sciences University Of Sumatra Utara, Medan, Indonesia 20155.

E-mail address: rangkuti@usu.ac.id.
} 
do it would be to begin work on both sides of the mountain after precise measurements. The two tunnels would meet in the middle, making a single one. If they do not meet, there will be two tunnels instead of one.

We would view grammatical traditions of the non-Western philosophers and scholars of language from both India and Arab as tunnellers through a mountain working at opposite sides of the same mountain with different tools, without even knowing if they are working in each other's direction. But both were doing their jobs with new ideas, digging as profoundly as possible with an equal commitment.

In the Western tradition, the use of technical term "linguistics", goes back to the beginning of the nineteenth century when Ferdinand de Saussure, known as father of modern linguistics, developed structuralist school of thought and established linguistics as a major intellectual discipline. We are therefore wary of using the term "Indian Linguistics" because it will guide our perspective from the study of language that came with Saussure. We would prefer to use the term 'grammatical tradition', for when viewed from the perspective of grammatical tradition, it not only tells us about language but also about "the religion, thought, ideology and aesthetics." [15]. Indeed the rapprochement between the two approaches, viz. Linguistics and grammatical tradition, is a necessary condition for understanding the fruitful cross-fertilization between these two modes of study, but it is important to understand that any such rapprochement must respect theoretical integrity of each other, and it is also equally important to "avoid the temptation of trying to construct non-Western grammatical theory in the image of Modern linguistic approaches, often in a violent or Procrustean fashion [15].

Greek culture was linguistically self-centred and monoglot. Etymology, phonetics (pronunciation) and grammar have been the three main aspects of language study that received much attention among the early Greeks. Although they recognized that languages change in the course of time, they treated etymology not as an inquiry into the history of a word but as a search for the 'true' meaning. Over the years, this perspective of the Greeks, however, lost its sheen and disappeared from the frame of reference. Though their interest in etymology certainly generated "a lot of enthusiasm" but "little of value was achieved [11]." In the field of phonetics, the ancient Greek scholars made progress that was of great value. But they also suffered because of "several serious omissions of factual observations" particularly with reference to their "classifications and descriptions" in terms of "impressionistic acoustics" without providing any "adequate technical terminology [11]." This has been in sharp contrast to the ancient Indians and the Arabs who were successful in providing the classification and description in terms of articulations.

The Greek (and the Romans), however, produced best work in the field of grammar. The commonplace philosophical speculation of Greek was a debate whether language was governed 
by 'nature' or 'convention' and the necessary connection between the meaning of a word and its form. Naturalists maintained that all words actually signify things. This may not always be evident to a common man because it is the philosopher's gaze that can discern the 'reality' that "lay behind the appearance of things [10]."

Their fierce debate over the dichotomies between nature or physis as against convention or nomos or thesis and regularity or analogia as against irregularity or anomalia represented formalized debates leading to the linguistic controversy of antiquity, which had locked the adherents in a permanent argument [11].

The concern of the non-Western Indian scholars of language sciences was not with language; rather they had a larger philosophical outlook and were, therefore, more concerned with the composition of the physical world and how language is related to the universe. The relationship centered on the Word and Meaning. The Physis-Nomos controversy in the Greek philosophy regarding how words acquire meaning further accentuated the non-Western scholars' concern with the nature of universe and exploring how the workings of nature are reflected in language. Their debates on anomaly vs analogy emerged in response to this primary concern with nature of universe. The analogists believed that there are no laws or regularity to be discovered in nature. The anomalists were of the view that regularities are not "haphazard but the consequence of inexorable laws."

Ideas of analogy and anomaly developed rivalry between different philosophical schools in the Arab world, more specifically in the school of Basra. One school of thought adhered to the analogist's views which placed emphasis on the "strict regularity and the systematic nature of language as a means of logical discourse about the world of phenomena [11].” The other school of thought, represented by a rival group of scholars in Kūfa, subscribed to the anomalists' views which laid stress on the diversity of language "including dialectal variations and textual occurrences as they were accepted [11]."

These ideas of analogy and anomaly were reflected in the Arab grammatical scholarship quite independent of the Greek philosophy and Greek science. This is quite in contrast with the Latin grammarians which is said to be modelled on Greek philosophy.

The most interesting non-Western grammatical tradition-and the most original and independent - is that of India, which dates back to at least two- and one-half millennia. It culminates with the grammar of Panini, of the 5th century BCE.

One can discern the impact of the non-Western Sanskrit tradition on modern linguistic scholarship in three major ways: As soon as Sanskrit became known to the Western learned world, the unravelling of comparative Indo-European grammar ensued, and the foundations were laid for the whole 19th-century edifice of comparative philology and historical linguistics. 
But, for this, Sanskrit was simply a part of the data; Indian grammatical learning played almost no direct part. The native tradition of phonetics in ancient India was recognized by the nineteenth-century workers, which was considered vastly superior to Western knowledge, and this had important consequences for the growth of the science of phonetics in the West. In the rules or definitions (sutras) of Panini one may find a remarkably subtle and penetrating account of Sanskrit grammar. Here the construction of sentences, compound nouns, and the like are explained through ordered rules operating on underlying structures. The rule-driven formalism bears an uncanny resemblance with the formalisms operating in modern theoretical linguistics carried out under Chomskyean framework.

In the Indian intellectual tradition, the origin of language study and its different branches are rooted in the source civilizational texts like the Veda ${ }^{*}$ and the Agamas ${ }^{\dagger}$ To maintain and interpret the vast oral Vedic verbal discourse, the Indian philosophers realized to have knowledge in different dimensions of language. Maintenance of texts in the oral tradition depended on a complete understanding of:

the phonetics of speech,

the morphology of continuous utterances that in turn depended on, and

an understanding of meanings of utterances/ words.

Since oral transmission is the means to continue the tradition alive and make the knowledge accessible to others, phonetics and phonology are the first language science to have developed. Every Vedic text has a corresponding prättşkhya text in order to recite the Vedic verses with the inputs of norm and variations and to keep the text intact.

\section{Methods}

Indian theories of meaning are based on empirical foundation, which is quite in contrast to some Western theories. Sound empirical foundation has been possible because the proponents of Indian theories of meaning were familiar with the techniques and results of Paninian Linguistics. In fact, they were predisposed with the wholistic understanding of phenomena surrounding nature and language.

\footnotetext{
*Veda- knowledge texts which are considered the sources of Hindu religion. Basically, the number of Vedas are four-Rg Veda, Yajur Veda, Saama Veda and Atharva Veda.

$\dagger$ Aagama- source text of Indian culture and thought technically texts related to Tantra, also a valid means of knowledge.
} 
In this context it is equally important to note that Sanskrit terms for meaning are, in general, used only for words, sentences, and other elements of language. There are no expressions in Sanskrit corresponding to English expressions such as 'the meaning of existence', or 'the meaning of life'. These are the expressions that have troubled the West "not only in popular speculation but also in philosophy [14]."

It is only after centuries of efforts at interpretation that theories of meaning arise. India is no exception here. Brähmanas - a class of prose works, which started from the beginning of the first millennium BC, is considered as the earliest Indian efforts at interpretation. A typical Brāhmana passage explains why a particular rite is performed and why a particular Vedic phrase or mantra $\bar{a}$ is recited at that time. Nirukta gives more systematic etymological interpretations of a portion of the vocabulary of Rgveda. It addresses the problems of ambiguous words, i.e. those words that have two or more distinct meanings, by providing different etymologies for each of these meanings. Discussions of general nature on the parts of speech and their meanings can also be seen in these early efforts towards interpretation and evolving theories of meaning. For example, 'verbs' are said to express 'becoming' and 'nouns' are said to express 'being'. Yaskā 's commentary on the Nighanțu lists Vedic words and provides a semantic field of these words. For instance, it has grouped 23 words to cover the semantic field for 'night' in the first section of Nighantu.

\section{Result and Analysis}

Although the Indian Grammatical Tradition started as an ancillary science to the Vedas, it maintained its difference from the other ancillary sciences by neither letting itself restricted to a particular school nor by providing separate grammar for each of the schools. On the contrary, it encompassed traits of all the schools. It is this inclusive disposition that allowed language sciences to emerge as an independent science. It, thus, attained full freedom from the Vedas. Contrary to other philosophical schools, grammarians believe the relationship exists between word and meaning is siddha 'given'. The term siddha means nitya, which refers to unchanging and immovable ideas or entities, such as the heaven is there, the earth is there.

Patañjali (150 BC) has been most explicit in this regard. He, according to [14], has held the view that the source of empirical material is the ordinary speech. Patañjali believed that knowledge can be derived from the ordinary speech upon which the study of grammar is based.

By using pot as a metaphor, he writes: 'A man who wants to use a pot, goes to the house of a potter and says 'Make a pot, I want to use it.' But a man who wants to use words does not go to the house of a grammarian and says 'Make words, I want to use them.' When he wants to express a meaning, he uses the appropriate word (Mahābhāşya 1.1.1, cited in [14]. 
Pạnini's grammar deals with both word meaning and sentence meaning. While the word meaning is fraught with many problems and the Indian theorists of meaning were aware of these problems, what occupied the center stage was the sentence meaning.

What determines or establishes 'sentencehood'? The early grammarians considered a sentence as merely a 'collection of words' or 'what possesses a finite verb' [14]. Mimansā school went beyond this simplistic notion of a sentence. Instead they evolved additional criterion called 'mutual syntactic expectance' (or ākān்kșa) for determining full 'sentencehood'. They argued that neither a collection of words (cow, horse, man, elephant) nor one that possesses a finite verb (cow irrigates man elephant) is a sentence. However, He irrigates with water is a sentence because it fulfils the criterion of 'mutual syntactic expectance' between all the words.

But can a full 'sentencehood' of a sentence be determined only by fulfilling this criterion? What if we have a sentence such as He irrigates it with fire? Can it be called a sentence? Although it is syntactically well-formed, semantically it is unacceptable. This sentence resonates the famous sentence given by Chomsky: Colourless green ideas sleep furiously.

The Indian theorists of meaning thus suggested another necessary criterion for determining the 'sentencehood', referred to as 'semantic compatibility' (or yogyatā), which is absent in the sentence He irrigates it with fire? But present in a sentence He irrigates it with water? [14].

In a grammatical work, prior to Patañjali, philosophical discussion revolving around the nature of word can be found in Samgraha, an ancient treatise.

However, any rigorous attempt at expounding the philosophy of Sanskrit grammar can be seen only in the Vākyapadīya of Bhartrihari. He has been mentioned by I-tsing during his visit to India. He is said to be an ancient grammarian-philosopher who represented Āgama school. It discusses nature of word and sentence. Philosophy of Bhartrihari is known as the philosophy of Śabda-Brahman. He neither affiliated with idealism nor materialism. This was the uniqueness of Bhartrhari's philosophy. His assertion that the word is the source of the world is a novel proposition. This idea of the worldly charged life of word finds its echo in what Bakhtin in 1981 observes with regard to words when he reminds us that 'All words have the 'taste' of a profession, a genre, a tendency, a party, a particular work, a particular person, a generation, an age group, the day and hour. Each word tastes of the context and contexts in which it has lived its socially charged life...' [3].

Unlike the Indian Grammatical Tradition which represented holistic approach to the study of language sciences, the Arabic Grammatical Tradition was considered by some scholars such as Baalbaki as representing a compartmentalized approach. This is evident in a much cited work of Sakkākī (d. 626/1229), Miftāh-al-'ulūm, where he not only points out the link between a number of linguistic 'ulūm, including șarf, naḥw, ma'ān̄ and bayān but also shows "how these 'ulūm 
have become isolated and compartmentalized." Ibn Khaldūn's (d. 808/1406) Muqaddimā also connects linguistic 'ulüm covering lexicology, grammar, rhetoric and literature. According to Baalbaki, "Even before Sakkākī, the trend was obviously to treat these 'ulūm as independent, though related fields of investigation." [9]

Though spatially and temporally separated, certain traits of similarity can be traced in both the Indian and the Arabic Grammatical Tradition. Like other sacred texts, Qur'an also gave rise to a tradition of linguistic exegesis and commentary, which mark the culmination of Arabic grammatical tradition at the end of the $8^{\text {th }}$ century. Sībawayhi's al-Kitāb provides description of Arabic based on: The text of the Qur'ān, the unattainable paragon of the art of language which has to be recited absolutely correctly.

Both of them placed emphasis on the study of the words and their scholarship to the study of language sciences was acknowledged as superior to the Western Grammatical Theory in respect to phonetics as they were successful in providing the classification and description in terms of articulations. Their concern with the sacred texts was not just with a view to preserving the linguistic sanctity but in a way to provide elaborate and rich description of use of language in the realm of poetic and rhetoric. Independently, they both studied the common language of the day. Hence, one of the sources of al-Kitāb was the ordinary speech of some native speakers, referred to as al- 'Arab, who were Bedouins from various tribes living around al-Bașra and spoke dialects of the old Arabic type [8].

Both always believed in the recognition and rules of recitation, called tajwwid. They shared a common concern with the preservation of the text, correct pronunciation. It is generally considered in Arab tradition that Abūl-Aswad al-Du'ali (who, according to al-Madā'ini, died in 688 in Basra) has been the originator of Arabic national grammar [12]. According to one tradition Abūl-Aswad gathered the notion of errors of speech called lahn, from the company of Hazrat 'Ali, as he was his faithful supporter. Lahn has been defined as "the melody in which is noticeable the deviation from normal pitch when singing [12]. We might consign this tradition to the realm of legend; the importance of the notion of lahn cannot be undermined. It is this concept that evokes sense of mistakes by "grammatical error" that presupposes an understanding of correct speech of the kind that had been found among the Indian antiquity.

The superiority of the Indian Grammatical Tradition over the Western Grammatical Theory with respect to study of phonetics has prompted some scholars to suggest that there has been the Indian connection in Arabic phonetic theories. As Danecki pointed out, "there are a number of parallel phenomena in description of articulatory processes to be observed"; and "if one considers the whole system of Indian and Arabic phonetics, no doubt should arise about the dependence of the Arabic teachings upon the Indians [9]." However, there are strong linguistic factors which raise doubts over the Indian influence on the Arabic phonetic work, the most 
serious being their observational failure to distinguish between voice-voiceless consonants. Although the Arabs treated the division of the consonants into two classes as important and they had correctly assigned the consonants to them, they had failed to diagnose the mechanics of the voice-voiceless distinction in the consonants.

There is yet another argument to the dimension suggesting that Arabic Grammatical Tradition grew separately and independently from Indian Grammatical Tradition is with regard to phonetic description of the Arabic script.

It may not be out of place to bring Bhandarkar's arguments regarding the origin of Indian alphabet, published with the same title in the Proceedings of Transaction of the First Oriental Conference held on the $5^{\text {th }}$ to $7^{\text {th }}$ November 1922 in Poona. In this article he traces the genesis of the two different scripts (or lipiss) found in the earliest inscriptions in India, namely Brāhmī written from left to right and recognized as the parent of all the scripts indigenous to India, and Kharoștī written from right to left. According to Bhandarkar, out of the three prominent theories it is the third theory that traces the Semitic origin, which is the accepted doctrine of all experts in Indian palaeography. Although originally put forward by Sir William Jones in 1806, the adherents of the theory of the Semitic origin such as Deeche \& Issac Taylor, Weber, Bühler, etc. even contested Cunningham and Thomas' claim that at no time Brāhmī was written from right to left. They clearly demonstrated that even the Brāhmī lipī was originally written from right to left.

Bühler had established his arguments on a firmer basis. According to him, not only the letters in the legend on a coin are to be read right to left, but even in Asioka's edicts single letters such as $d h, t$ and $o$ are sometimes found reversed. Reminiscences of the writing from right to left is further evident in conjunct consonants engraved in Asoka's inscriptions. The conjunct consonants must be so written as to follow the order in the pronunciation of its sounds. For instance, Bhandarkar points out that the letter $t$ in the conjunct consonant tpa must come above $p, s$ must come above $t$ in the conjunct consonant sta, and $v$ above $y$ in the conjunct consonant vya in left to right script. As a rule, the letter that is pronounced first is placed below and not above the second letter. Such a reversal of the process is possible only in the mode of writing from right to left. According to Bhandarkar, "the argument that the ancient alphabet of India always ran from left to right which was urged by Cunningham \& Thomas against its foreign origin was completely demolished by the evidence adduced by Bühler and Wickremasinghe [the learned editor of the Epigraphia Zelynica] [4]." 


\section{Conclusion}

From a broad perspective, language study relates itself to both ontology and epistemology. Both ontological and epistemological investigations have been the subject of debate and discussion in different civilizations producing a number of grammatical traditions other than the West. Arab, China, India and the ancient Near East can also boast of language traditions of greater antiquity. In terms of richness of insight and comprehensiveness of scope, both India and the Arab compete on equal terms with the West, where each grew independently of the others and for the most part developed separately, drawing on the resources of the culture within which it grew. Hence, there is strong need to have a study of comparative grammatical theory to which Indian, Arabs and Chinese also belong, centering on the questions of: What has been the importance of these theories for an understanding of modern linguistics? To what extent do common descriptive and explanatory categories appear in historically unrelated linguistic theory, and if they do, why? This perspective would bring new dimension to the study of linguistic theory and would not remain at the level of redressing the overwhelming emphasis on the European tradition in the study of history of linguistics.

\section{REFERENCES}

[1] Baalbaki, R. (ed.) The Early Islamic Grammatical Tradition. Great Britaib and U.S.A.: Ashgate Publishing Company. 2007.

[2] Baalbaki, R. The relation between Nahw and Balaga: A comparative study of the methods of Sibawayhi and Gurgani. In Baalbaki (ed.) Pp. 186-203.2007.

[3] Bakhtin, M.M. The Dialogic Imagination. Austin, TX: University of Texas Press.1981.

[4] Bhandarkar, D.R. Origin of Indian Alphabet. In the Proceedings of Transaction of the First Oriental Conference held on the $5^{\text {th }}$ to $7^{\text {th }}$ November 1922 in Poona. Poona: Bhandarkar Oriental Research Institute. Pp. 305-318. 1922.

[5] Deshpande, Madhav M. Ancient Indian Phonetics. In Koerner and Asher (eds.). Indian Grammatical Tradition. 2014.

[6] Online Available: http://shodhganga.inflibnet.ac.in/bitstream/10603/17616/11/11_chapter 201.pdf [Accessed: January 15, 2016].

[7] Koerner, E.F.K. and R.E. Asher (eds.) Concise History of the Language Sciences: From the Sumerians to the Cognitivists. Elsevier. 2014.

[8] Law, V. Indian Influence on Early Arab Phonetics - or Coincidence? In Baalbaki (ed.). Pp. 121-133. 2007.

[9] Levin, A. The Fundamental Principles of the Arab Grammarians' Theory of 'Amal. In Baalbaki (ed.). Pp. 205-223. 2007.

[10] Lyons, J. Introduction to Theoretical Linguistics. Cambridge: Cambridge niversity Press. 1971

[11] Robins, R.H. A Short History of Linguistics. London, New York: Longman.1979

[12] Rundgren, F. On the Greek influence on Arabic grammar. Baalbaki (ed.). Pp. 75-99. 2007

[13] Sastri, G. Philosophy of Bhartrhari. Journal of the Asiatic Society. Letters. Vol. XXII, No. 1. 1956

[14] Staal. J. F. Indian Theories of Meaning. In Koerner and Asher (eds.). Pp. 64-71.2014

[15] Suleiman, Y. Arabic Grammar and Linguistics. London and New York: Routledge. 1999 